\title{
ПРОБЛЕМАТИКА УНИФИКАЦИИ И СТАНДАРТИЗАЦИИ В СОВРЕМЕННОМ ПРОЕКТИРОВАНИИ
}

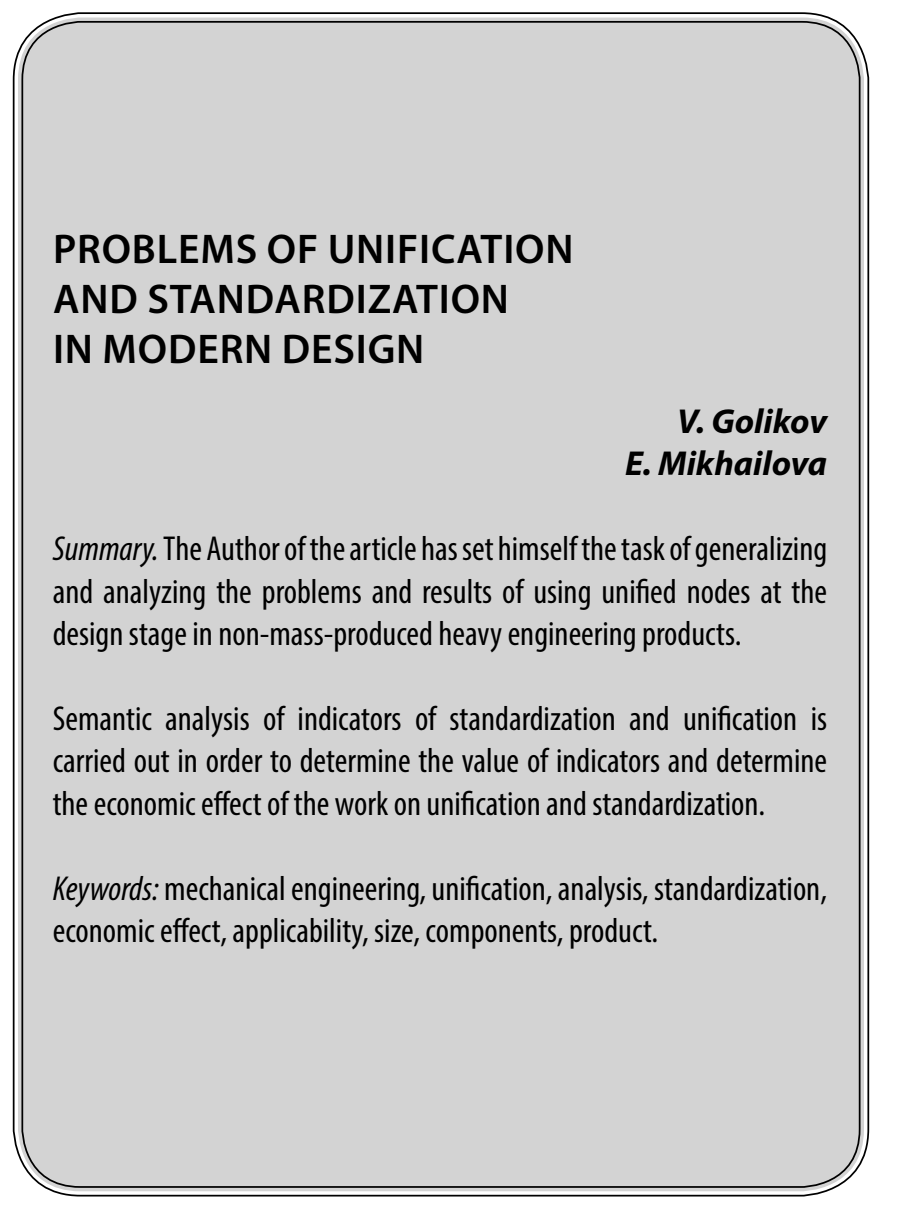

\section{Введение}

B мировом производстве продукции автомобилестроение занимает огромную часть. Можно с полной уверенностью сказать, что автомобиль является наиболее массовым среди производимых изделий машиностроения. Общий объем производства автомобилей составляет свыше 66 млн. в год, а в эксплуатации находится свыше 600 млн. автомобилей. Если бы автомобильная промышленность была государством, то это была бы шестая экономика в мире [1]. Даже незначительные выгоды, полученные при производстве автомобилей, а также оптимизации их конструкций и умноженные на их количество могут дать значительный экономический эффект и социальную выгоду для людей.

Унификация изделий - приведение изделий к единообразию на основе установления рационального числа их разновидностей [3].
Голиков Владислав Андреевич

Ассистент, Московский авиационный институт (национальный исследовательский университет) fordik08@mail.ru

Михайлова Екатерина Вячеславна Ассистент, Московский авиационный институт (национальный исследовательский университет) evmihailova@inbox.ru

Аннотация. Автор статьи поставил перед собой задачу обобщения и анализа проблем и результатов применения унифицированных узлов на этапе проектирования в изделиях тяжелого машиностроения не серийного изготовления.

Семантический анализ показателей стандартизации и унификации проводится с целью определения значения показателей и определения экономического эффекта от проведения работ по унификации и стандартизации.

Ключевые слова: машиностроение, унификация, анализ, стандартизация, экономический эффект, применяемость, типоразмер, составные части, изделие.

В зависимости от поставленных задач унификация изделий может проводиться по назначению, средствам обеспечения и обслуживания, агрегатам и узлам определенного функционального назначения, условиям производства, а также по другим признакам.

Основными целями унификации являются:

- ускорение темпов научно-технического прогресса в отраслях промышленности за счет сокращения сроков разработки, подготовки производства, изготовления, проведения технического обслуживания и ремонта изделий;

- создание условий при проектировании и производстве для обеспечения высокого качества изделий и взаимозаменяемости их составных частей в эксплуатации;

- повышение экономической эффективности создания и эксплуатации изделий за счет снижения затрат в процессе проектирования изделий, из- 

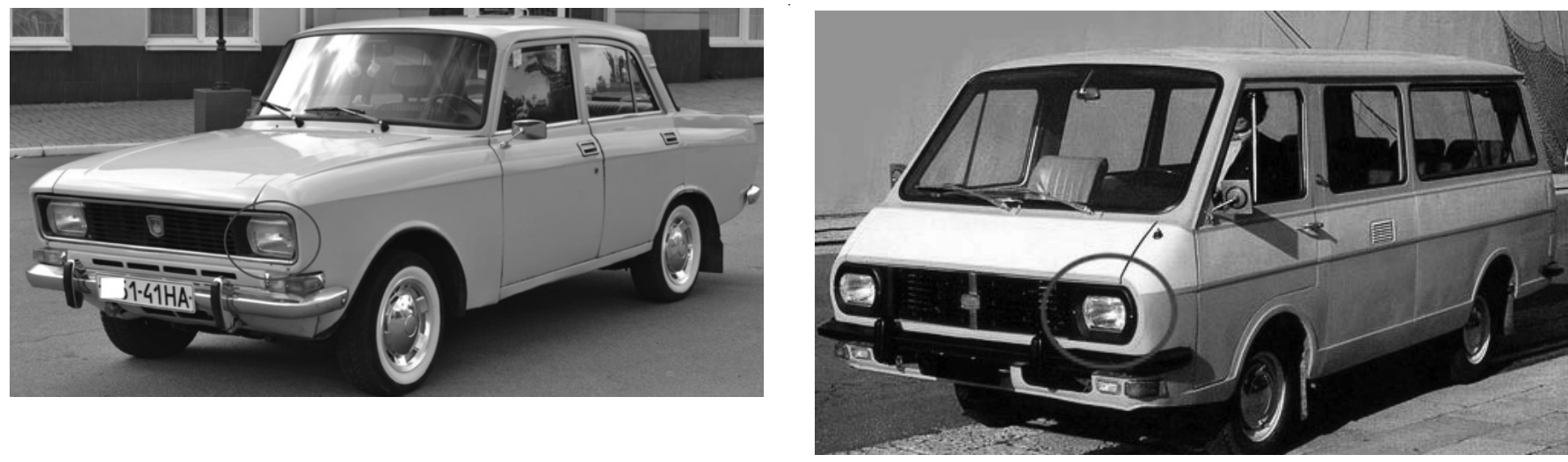

Рис. 1. Унификация деталей кузова на разных автомобилях.

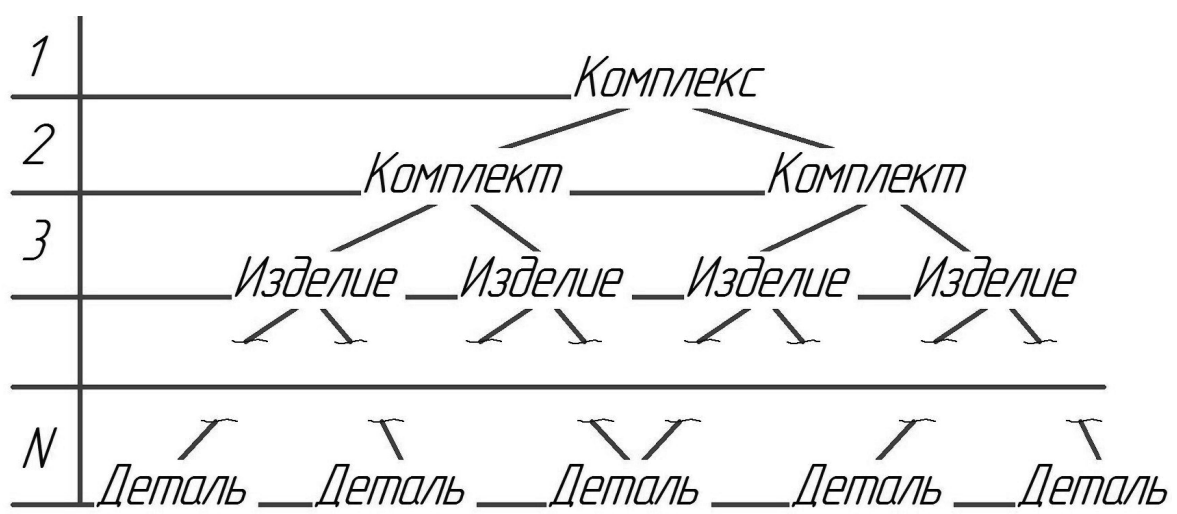

Рис. 2. Декомпозиция составных частей.

готовления их в условиях специализации производства и технического обслуживания [4].

При проведении анализа необходимо наличие следующих документов:

- техническое задание на выполнение работ;

- материалы рабочей документации.

\section{Обоснование показателей уровня}

станАартизашии и унификашии

Разработка изделий должна осуществляться с использованием заимствования конструктивных и технологических интеллектуальных решений, унифицированных узлов и деталей, а также математического и программного обеспечения изделий аналогичного назначения, соответствующих современному уровню развития технологий. Варианты заимствований элементов экстерьера автомобилей во времена Советского союза представлены на рис. 1.

Применение материалов, посадок, резьб, покрытий, а также комплектующих изделий должны проводиться в соответствии с ограничителем применяемости материалов и действующей нормативно-технической документацией организации-изготовителя.

Автомобиль можно декомпозировать на платформу и кузов. Платформа представляет собой совокупность агрегатов выполняющих в автомобиле определенные функции [2]. Назовем эти агрегаты модулями, как это делается в современных каталожных описаниях. Таким образом, модулем можно назвать любую часть, отделяемую без разрушения от некоторого целого. Определив эту часть теми функциями, которые она выполняет в целом, мы можем получить некую иерархию узлов, вплоть до деталей (рис. 2).

Конструкция модулей при изготовлении не должна требовать оригинальной технологии и предусматривать типовые технологические процессы организации-изготовителя и типовые стандартные средства измерения и методы испытаний.

Разрабатываемые оригинальные модули должны иметь перспективу применения в аналогичных дальнейших разработках. 
Расчет количественных показателей стандартизации и унификации

Коэффициент применяемости составных частей изделия $\mathrm{W}_{n p}$ определяется по типоразмерам в процентном выражении по формуле [5]:

$\mathrm{W}_{\text {пр }}=\frac{h-h_{0}}{h} \cdot 100 \%$

где $h=h_{\mathrm{o}}+h_{\mathrm{s}}+h_{\mathrm{y}}+h_{\text {п }}+h_{\mathrm{cт}}$ - общее количество типоразмеров составных частей агрегата.

где $h_{o}$ - количество оригинальных типоразмеров;

$h_{3}$ - количество заимствованных типоразмеров;

$h_{y}$ - количество унифицированных типоразмеров;

$h_{n}$ - количество покупных типоразмеров;

$h_{c m}$ - количество стандартных типоразмеров.

Коэффициенты применяемости по группам составных частей определяются в процентном выражении по формулам:

Коэффициент применяемости заимствованных типоразмеров

$$
W_{\text {mp.3 }}=\frac{h_{3}}{h} \cdot 100 \% \text {. }
$$

Коэффициент применяемости унифицированных типоразмеров

$$
W_{\text {mp.y }}=\frac{h_{y}}{h} \cdot 100 \%
$$

Коэффициент применяемости покупных типоразмеров

$$
W_{\text {пр.п }}=\frac{h_{\text {пा }}}{h} \cdot 100 \%
$$

Коэффициент применяемости стандартных типоразмеров

$$
W_{\text {mp.cт }}=\frac{h_{\text {cт }}}{h} \cdot 100 \% .
$$

Коэффициент повторяемости составных частей агрегата

$$
W_{\text {п }}=\frac{H}{h}
$$

где Н - общее количество составных частей всех категорий агрегата, определено по формуле

$$
H=H_{\mathrm{o}}+H_{3}+H_{\mathrm{y}}+H_{\mathrm{m}}+H_{\mathrm{cT}}
$$
стей.

где $H_{o}$ - количество оригинальных составных ча-

$H_{3}$ - количество заимствованных составных частей.
$H_{y}$ - количество унифицированных составных частей.

$H_{n}$ - количество покупных составных частей.

$H_{c m}$ - количество стандартных составных частей.

\section{Ошенка экономической}

эффективности работ

по станАартизации

и унификации

Экономический эффект (далее ЭЭ) от работ по унификации определяется по формуле:

$$
\ni=Э_{\text {Док }}+Э_{\Pi р}+Э_{И с}
$$

$Э_{\text {Док, }} Э_{\text {Пр }}, Э_{И с}-Э Э$ от работ по унификации при разработке документации, изготовлении и испытаниях.

ЭЭ при разработке документации обуславливается экономией средств за счет применения стандартных, унифицированных, заимствованных и покупных составных частей и определяется по формуле:

$$
\exists_{\mathrm{kд}}=\pi \sum_{i=1}^{H} Y_{i} \cdot U,
$$

Л - коэффициент, учитывающий фактическую экономию при проектировании агрегата;

$H$ - количество примененных стандартных, унифицированных, заимствованных, покупных типоразмеров составных частей;

$Y_{i}$ - трудоемкость разработки одного типоразмера, чел. день;

\section{$U$ - стоимость человека-дня.}

ЭЭ от работ по стандартизации и унификации при изготовлении опытного образца образуется за счет использования стандартных, унифицированных, заимствованных и покупных составных частей и определяется по формуле:

$$
\exists_{\text {Пр }}=\mathrm{C}_{\text {Пр }} \frac{\alpha \cdot W_{\text {пр }}}{\left(1-x \cdot W_{\text {пр }}\right)} \cdot N,
$$

$C_{П р}$ - затраты на изготовление;

$N$ - количество образцов;

$x$ - коэффициент, учитывающий снижение затрат на изготовление опытного образца за счет применения стандартных, унифицированных, заимствованных и покупных составных частей;

$W_{n p}$ - коэффициент применяемости по типоразмерам. 
Для эксплуатации используются все изготовленные изделия, вследствие этого экономический эффект от работ по унификации при испытании $Э_{u c}$ принимается равным нулю.

$$
\ni_{u c}=0
$$

\section{ВывО $\triangle \mathrm{b}$}

Результатом проведенного анализа служит реализация принципов технически целесообразной стандартизации и унификации составных частей и требований тех- нического задания, на проведение работ выполненных в полном объёме.

В результате, необходимо достижение коэффициентов применяемости $\mathrm{W}_{n p}$, повторяемости $\mathrm{W}_{n}$ минимально разрешенного значения.

Экономический эффект от работ по унификации опытных образцов изделий находится в прямой пропорциональной зависимости от количества сокращенных, в результате унификации, опытных образцов изделий для проведения испытаний.

\section{ЛИТЕРАТУРА}

1. Гадельшин Т. К. Параметрическая унификация конструктивных параметров автомобиля при его конструировании и производстве / Д. Т. Гадельшин / Известия МГТУ «МАМИ» — 2008. — № 1(5). — с 12.

2. Никанорова Л. В. Унификация в автомобилестроении / М. В. Лосева, А. С. Сизенков / Вестник АнГТУ.— 2015.— № 9.—c. 197.

3. ГОСТ 1.1-2002 Межгосударственная система стандартизации. Термины и определения. введ. 2003-07-01- М.: Стандартинформ, 2003.

4. ГОСТ 23945.0-80 Унификация изделия. Основные положения. введ. 1980-07-01.—М: Издательство стандартов, 81.

5. ГОСТ Р 56470-2015 Документация конструкторская изделий ракетно-космической техники. Организация и порядок проведения экспертизы на соответствие требованиям стандартизации, унификации и каталогизации. введ. 2016-01-01 — М.: Стандартинформ, 2016.

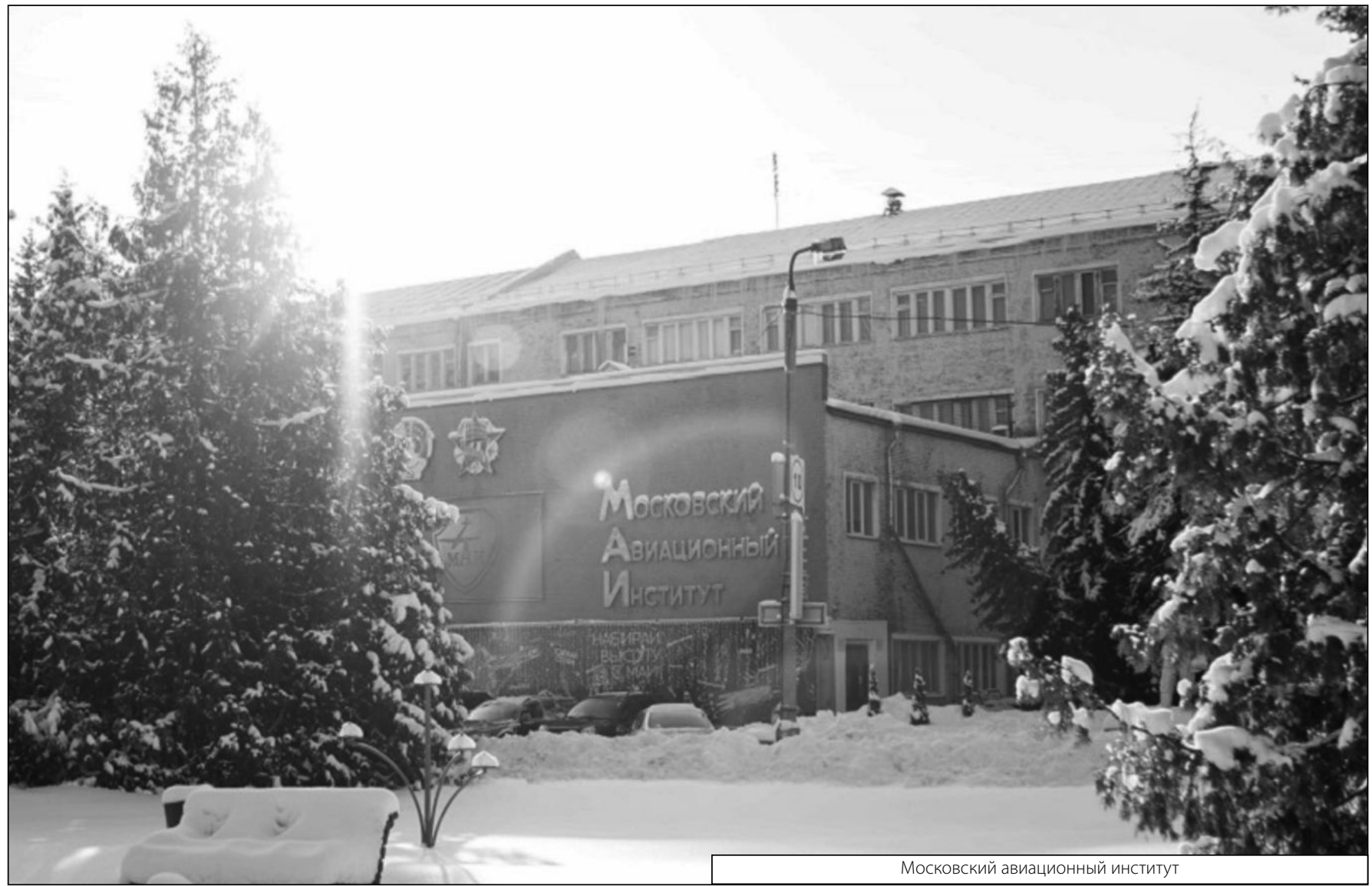

